\title{
Self-Esteem and Personality Traits as Predictors of Mental Well Being
}

\author{
Bindu Kumari $^{1 *}$, Rajnee Sharma ${ }^{2}$
}

\section{ABSTRACT}

Mental Well-Being is an integral part of good mental health and indicator of the ability of the individuals to cope up with daily stresses and work productively. Many predisposed and acquired factors influence the Mental Well-Being of an individual. The present study investigated the Self- Esteem and Personality traits as the predictors of mental well being. The results indicated that Neuroticism, Extraversion and Openness to experience came out as significant predictors of Mental Well-Being.

Keywords: Self esteem, Personality, Mental Well Being.

Mental well being refers to the ability of an individual to cope up with daily stresses and work productively (WHO, Helinski, 2005). Self related health, subjective health complaints and life satisfaction are the indicators of mental well-being (WHO, HBSC, 2007). Adolescents and young adults undergo considerable changes during puberty. A good sense of Mental Well Being will improve their social relationships, problem solving skills and develop a sense of purpose in them (Olweus, 1994). Many studies provide evidences for the relationship between self esteem, personality traits and well being. The opinion and judgment an individual makes about him/ herself also has an impact on his/ her Mental Well-Being. The positive self esteem, internal standards and aspirations are the active contributors for well being (Glick \& Zigler, 1992). Self esteem and dispositional optimism were found to be related with subjective well being (Lucas et al. 1996). Tudor (1996) investigated and found self identity; self concept and self esteem are the basic elements of mental health. Self esteem has been found the key predictor of happiness (Furnham \& Cheng, 2000). Zimmerman (2000) investigated that the share of variance of self esteem in both Mental Well Being and happiness is significant. The development and understanding of self esteem, its outcomes and its active promotion and protection is very much necessary for improving mental and physical health (Mann, Hosman, Schaalma \& de Varies, 2004). Self esteem and optimism also have both main as well as moderating effects on well-

\footnotetext{
${ }^{1}$ Assistant Professor, Hindu Girls College, Sonepat

${ }^{2}$ Lecturer, GGHS, Untlodha

*Responding Author

(C) 2016 I B Kumari, R Sharma; licensee IJIP. This is an Open Access Research distributed under the terms of the Creative Commons Attribution License (http://creativecommons.org/licenses/by/2.0), which permits unrestricted use, distribution, and reproduction in any Medium, provided the original work is properly cited.
} 
being although these are gender specific effects. The low self esteem and optimism negatively effects emotional exhaustion and mental distress among male employees and for females, optimism moderated the relation between work pressure, job insecurity and organizational climate on mental distress (Makikangas \& Kinnunen, 2003). The personality dispositions such as Extraversion, Neuroticism and Self-esteem can influence the level of Subjective well being markedly (Diener, Oishi \& Lucas, 2003). Mental well being is influenced by the dispositional and acquired factors and various studies provide evidence in support of this. The relationship between Big Five Personality traits and Subjective well being was examined and it was found that extraversion and Neuroticism have been linked with Subjective well being (Costa \& McCrae, 1980). DeNeve \& Copper (1998) stated that focusing on few Personality traits may lead to the oversimplifications of association patterns of Personality traits and Subjective well being. It was reported that about .20 correlation of agreeableness and conscientiousness with Subjective well being measures. The Subjective well being has moderate correlation with a number of narrow personality traits such as Hardiness, Locus of control, Repressive defensiveness, trust and desire to control. The correlation of Extraversion with pleasant effect was found to be .38 at zero order level in a Meta analytical review (Lucas \& Fujita, 2000). The Mental well being is also associated with physical \& social factors in the environment. The sense of overcrowding in home, fear of crime, neighbours voice, escape facilities such as green spaces and community facilities are also important factors linked with Mental Well Being showing its connection with physical and social environment (Guite, Clark \& Ackrill, 2006).

The present study aims to find out the relationship between Self esteem, Personality and Mental Well Being. Personality traits play a significant role in determining why certain people are more happy and satisfied with their lives. Self esteem is a crucial, protective and non specific risk factor of mental and physical health. The dynamics of self esteem and Personality may emerge as significant predictors of Mental well being in adolescents and young adult girls areas of Haryana. It is important to understand the predictive value of Self Esteem \& Personality so that they can be considered as core elements of Mental well being promotion.

\section{OBJECTIVE OF THE STUDY}

1. To examine the predictive value of big five Personality Traits for Mental Well Being.

2. To examine the predictive value of Self-esteem for Mental Well Being.

\section{Hypothesis}

1. There is significant predictive value of big five Personality traits for mental well being.

2. There is significant predictive value of Self-esteem for mental well being.

\section{METHOD}

\section{Sample}

Purposive sampling was done for the fulfillment of purpose of study. A total of 107 undergraduate students whose age range between 16-20 years from Hindu Girls College, Sonepat 
served as sample for the study. Questionnaires were distributed to 150 students in college and 43 were discarded because of incomplete questionnaires.

\section{Instruments}

The Self Esteem Inventory by Virk \& Chauhan (2003) having 20 items was used for assessing Self Esteem. It is a self report method and subject has to tick on boxes against yes or no responses.

The Big Five Factor (Dimensions) of Personality Inventory by Goldberg, 1993 having 44 items. The items were rated on a five point scale.

The Warwick Edinburgh Mental Well-Being Scale abbreviated as WEMWBS by NHS Scotland, University of Warwick and University of Edinburgh, 2006 having 20 items. The items were rated on five point scale and subject has to describe the experience of each over the last two weeks.

\section{ANALYSIS}

Regression analysis was used to examine the predictive value of Self-esteem and personality traits for mental well being.

Table 1: Correlation Coefficients for self esteem, personality traits and mental well being

\begin{tabular}{|c|c|c|c|c|c|c|c|}
\hline 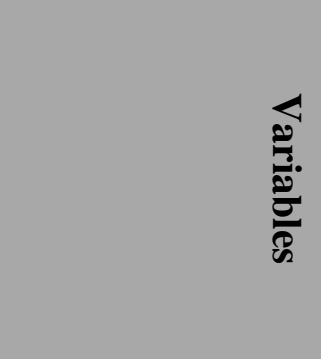 & 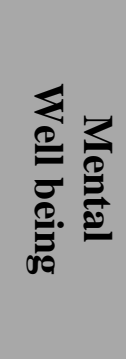 & 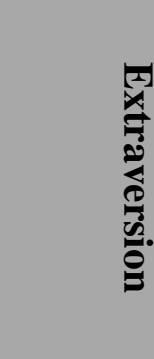 & 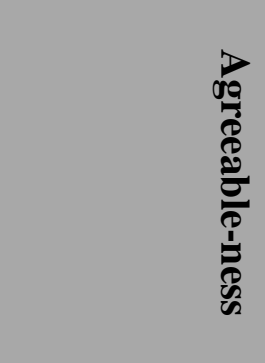 & 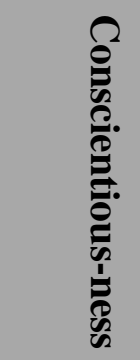 & 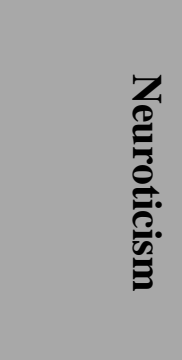 & 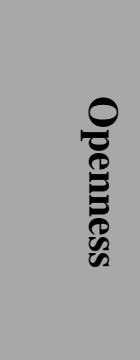 & 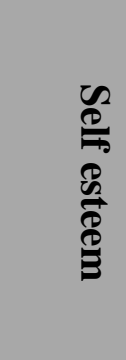 \\
\hline Mental well being & 1.0 & -.086 & .020 & $.141 * *$ & $-.460 * *$ & $.365 * *$ & $.144 * *$ \\
\hline Extraversion & -.086 & 1.000 & $.209 * *$ & $.245 * *$ & $-.171^{*}$ & .009 & .060 \\
\hline Agreeableness & .020 & $.209 * *$ & 1.000 & $.382 * *$ & -.019 & .107 & $.192 *$ \\
\hline Conscientiousness & $.141 * *$ & $.245 * *$ & $.382 * *$ & 1.000 & $-.176^{*}$ & .116 & $.293 * *$ \\
\hline Neuroticism & - & $-.171 *$ & -.019 & $-.176 *$ & 1.000 & -.122 & -.099 \\
\hline Openness & $.365 * *$ & .009 & .107 & .116 & -.122 & 1.000 & .107 \\
\hline Self esteem & $.144 * *$ & .060 & $.192 *$ & $.293 * *$ & -.099 & .107 & 1.000 \\
\hline
\end{tabular}

**. Correlation is significant at the 0.01 level (2-tailed).

*. Correlation is significant at the 0.05 level (2-tailed).

The table one illustrates a strong positive relationship between Conscientiousness, Openness to Experience and Self-Esteem with Mental Well Being. However, Neuroticism has a significant 
negative relation with Mental Well Being. The results depict that Extraversion and Agreeableness have no significant correlation with Mental Well Being. Agreeableness and Conscientiousness have significantly positive relation with Self-Esteem whereas no significant relation between Neuroticism, Extraversion, Openness to Experience and Self-Esteem was found. Extraversion was found to have significantly positive association with Agreeableness and Conscientiousness and negative association with neuroticism. Extraversion is not significantly related to Openness to Experience. Agreeableness has strong positive association with Extraversion and Conscientiousness. Conscientiousness depicted significant positive relation with Extraversion and Agreeableness and significant negative with Neuroticism and vice versa. Openness to Experience was found to have no significant relationship with other personality traits.

Table 2: Model Summaries of Mental wellbeing

\begin{tabular}{|c|c|c|c|c|c|c|c|c|c|c|}
\hline \multirow[t]{2}{*}{ Model } & \multirow[t]{2}{*}{$\mathbf{R}$} & \multirow[t]{2}{*}{$(\mathrm{R})^{2}$} & \multirow{2}{*}{$\begin{array}{l}\text { Adjusted } \\
(\mathrm{R})^{2}\end{array}$} & \multirow{2}{*}{$\begin{array}{l}\text { Std. } \\
\text { Error of } \\
\text { the } \\
\text { Estimate }\end{array}$} & \multicolumn{5}{|c|}{ Change Statistics } & \multirow{2}{*}{$\begin{array}{l}\text { Durbin - } \\
\text { Watson }\end{array}$} \\
\hline & & & & & $\begin{array}{c}(\mathrm{R})^{2} \\
\text { Change }\end{array}$ & $\begin{array}{c}\text { F } \\
\text { Change }\end{array}$ & df 1 & df 2 & $\begin{array}{c}\text { Sig. F } \\
\text { Change }\end{array}$ & \\
\hline 1 & $.460 \mathrm{a}$ & $\begin{array}{c}.21 \\
1\end{array}$ & .204 & 6.811 & .211 & 28.138 & 1 & 105 & .000 & \multirow[t]{2}{*}{2.145} \\
\hline 2 & $.555 b$ & $\begin{array}{c}.30 \\
8\end{array}$ & .295 & 6.411 & .097 & 14.519 & 1 & 104 & .000 & \\
\hline 3 & $.578 c$ & $\begin{array}{c}.33 \\
5\end{array}$ & .315 & 6.317 & .027 & 4.117 & 1 & 103 & .045 & \\
\hline
\end{tabular}

a. Predictors: (Constant), Neuroticism

b. Predictors: (Constant), Neuroticism, Openness to experience

c. Predictors: (Constant), Neuroticism, Openness to experience, Extraversion

d. Dependent Variable: Mental Wellbeing

Table two depicts three models for prediction of Mental Well Being. Model one indicates Neuroticism as predictor of Mental Well Being. With $\mathrm{R}$ value equals to .460. Model two indicates Neuroticism and Openness to Experience both as predictors of Mental Well Being with $\mathrm{R}$ value equals to .555. Model three indicates Neuroticism, Openness to Experience and Extraversion as predictors of mental wellbeing with $\mathrm{R}$ value equals to.578. The value of $\mathrm{R}$ Square for first model is .211, which shows that neuroticism accounts for $21.1 \%$ change in mental wellbeing however, this value increases to .308 0r 30.8\% in model 2 and .335 in model 3. The result table depicts that neuroticism independently accounts for $21.1 \%$ change in mental wellbeing whereas the interaction of neuroticism and openness to experience accounts for an additional $09.7 \%$ increase of (30.8\% -21.1\%). Third model depicts that the interaction of neuroticism, openness to experience and extraversion accounts for an additional $.02 .7 \%$ increase of variance (33.5\% - 30.8\%). The mental wellbeing model summary revealed that the interaction of neuroticism, openness to experience and extraversion came out as significant predictors for 
mental well being with 33.5\% variance. The Durbin-Watson statistics is $2.145(3>2.145>1)$ which describes that the assumptions of independent errors is tenable.

\section{DISSCUSSION}

The results indicate that the interaction of Neuroticism, Openness to Experience and Extraversion came out as significant predictors for Mental Well-Being. It implies that the predisposed personality traits are important determinants of Mental Well-Being. Extravert individuals and individuals having openness to experience would have a good score on Mental Well-Being scale. The individuals having high score on Neuroticism would score low on Mental Well-Being scale. Diener, Oishi \& Lucas (2003) provided evidence for the same that Extraversion, Neuroticism \& Self-Esteem can influence Mental Well-Being level markedly.

\section{CONCLUSION}

The personality traits such as Openness to Experience, Extraversion \& Neuroticism are the important factors in determination of Mental Well-Being. We can predict the Mental Well-Being of individuals by knowing their personality traits. Clinical intervention for Neuroticism may help in Mental Well-Being of individuals which in turn will increase their ability to cope up with stress and live life productively.

\section{REFERENCES}

Costa, P. T., \& McCrae, R. R. (1980). Influence of extraversion and neuroticism on subjective well-being: happy and unhappy people. Journal of personality and social psychology, 38(4), 668.

DeNeve, K.M, \& Cooper, H. (1998). The happy personality: A meta-analysis of 137 personality traits and subjective well-being. Psychological Bulletin.66. 1128-1139.

Diener, E., Oishi, S., \& Lucas, R. E. (2003). Personality, culture, and subjective well-being: Emotional and cognitive evaluations of life. Annual review of psychology, 54(1), 403425.

Furnham, A., \& Cheng, H. (2000). Lay theories of happiness. Journal of happiness studies, 1(2), 227-246.

Glick M. and Zigler E. (1992). Premorbid competence and the courses and outcomes of psychiatric disorders. In: J. Rolf, A. S. Masten, D. Cicchetti, K.H. Nuechterlein, S. Weintraub (Eds), Risk and Protective Factors in the Development of Psychopathology. Cambridge University Press, Cambridge, 497-513.

Guite, H. F., Clark, C., \& Ackrill, G. (2006). The impact of the physical and urban environment on mental well-being. Public health, 120(12), 1117-1126.

Lucas, R. E., \& Fujita, F. (2000). Factors influencing the relation between extraversion and pleasant affect. Journal of personality and social psychology, 79(6), 1039.

Lucas, R.E., Diener, E \& Suh, E. (1996). Discriminant validity of well-being measures. Journal of Personality \& Social Psychology. 71. 616-628. 
Makikangas, A., \& Kinnunen, U. (2003). Psychosocial work stressors and well-being: Selfesteem and optimism as moderators in a one year longitudinal sample. Personality and individual differences. 35. 537-557.

Mann, M. M., Hosman, C. M., Schaalma, H. P., \& de Vries, N. K. (2004). Self-esteem in a broad-spectrum approach for mental health promotion. Health Education Research, 19(4).

Olweus, D. (1994). Bullying at school (97-130). Springer US.

Tudor, K. (1996). Mental health promotion: Paradigms and practice. Psychology Press.

World Health Organization (2005). Mental Health Declaration for Europe. Facing the Challenges, Building Solutions. Copenhagen, WHO Regional Office for Europe,2005. (http://www.euro.who.int/Document/MNH/edoc07.pdf, accessed 22 May 2008).

World Health Orgnaization (2007). Social Cohesion for Mental Well Being among adolscents. WHO/HBSC FORUM (2007).Copenhagen, WHO Regional Office for Europe, 2007.

Zigler, E. F., \& Glick, M. (2001). A developmental approach to adult psychopathology. John Wiley \& Sons.

Zimmerman, B. (2000). Self-efficacy: An Essential motive to Learn. Contemporary Educational Psychology 25, 82-91.

How to cite this article: B Kumari, R Sharma (2016) Self-Esteem and Personality Traits as Predictors of Mental Well Being, International Journal of Indian Psychology, Volume 3, Issue 3, No. 5, DIP: $18.01 .083 / 20160303$ 